\title{
Management of pulmonary metastases: a narrative review on the oncologist's perspective
}

\author{
Annarita Bottini ${ }^{1}$, Francesca Parisi ${ }^{2}$, Eugenia Cella ${ }^{1}$, Gianluca Sacco ${ }^{1}$, Carlo Genova ${ }^{2,3} \wedge$ \\ ${ }^{1}$ UOC Oncologia Medica 2, IRCCS Ospedale Policlinico San Martino, Genoa, Italy; ${ }^{2}$ UOC Clinica di Oncologia Medica, IRCCS Ospedale \\ Policlinico San Martino, Genoa, Italy; ${ }^{3}$ Dipartimento di Medicina Interna e Specialità Mediche (DiMI), Università degli Studi di Genova, Genoa, Italy \\ Contributions: (I) Conception and design: C Genova; (II) Administrative support: None; (III) Provision of study materials or patients: None; (IV) \\ Collection and assembly of data: A Bottini, F Parisi, E Cella, G Sacco; (V) Data analysis and interpretations: All authors; (VI) Manuscript writing: All \\ authors; (VII) Final approval of manuscript: All authors. \\ Correspondence to: Carlo Genova, MD, PhD. UOC Clinica di Oncologia Medica, IRCCS Ospedale Policlinico San Martino, Genoa, Italy; \\ Dipartimento di Medicina Interna e Specialità Mediche (DiMI), Università degli Studi di Genova, Largo Rosanna Benzi 10, 16132 Genoa, Italy. \\ Email: carlo.genova@hsanmartino.it.
}

Background and Objective: In a large proportion of patients affected by solid tumors, metastatic disease is identified at diagnosis; alternatively, cancer patients might develop metastases during their follow up after treatment of the primary tumor. Among distant metastases, pulmonary lesions are particularly relevant, as they are frequent in many solid malignancies. While the management of disseminated tumors relies mainly on systemic treatments with palliative intent, the interest in local treatments of single or limited pulmonary metastases (oligometastatic disease) has developed throughout years, either with curative intent or with the intent of prolonging survival. In spite of this growing interest, published scientific data on the oligometastatic setting are relatively limited, and randomized trials are particularly scarce; hence, the available evidence mostly relies on retrospective patient series. The aim of this review is to summarize the currently available data on the management of pulmonary metastases, with specific reference to oligometastases from the oncologist's point of view.

Methods: We evaluated the evidence supporting local approaches to pulmonary metastases, including surgery and radiation therapy, either alone or in combination to systemic treatments. In this context, we included a specific focus on colo-rectal cancer, as this was the first tumor in which regional approaches for pulmonary oligometastases were developed; furthermore, colo-rectal cancer provides an optimal model for describing the physiopathology leading to the development of pulmonary metastases and the local approaches to pulmonary metastases. In order to evaluate the most up-to-date information, we evaluated the available literature in English language published on PubMed between 2000 and 2021, identified during an informal search, and we assessed the most relevant international oncology meetings in the same time span to support our expert opinion.

Key Content and Findings: The content of this narrative review includes data on epidemiology and physiopathology of pulmonary metastases, as well as the most solid available evidence on loco-regional and integrated approaches to pulmonary oligometastases.

Conclusions: Based on the available evidence, the local management of pulmonary metastases, when feasible depending on limited size and number, controlled primary tumor, and absence of other metastatic lesions, appears to have a positive impact on patients' prognosis, although the robustness of these data is limited by the general lack of prospective trials. Results from studies designed to assess the effectiveness of combined local and systemic treatments, especially in the era of biological agents and cancer immunotherapy, albeit difficult to conduct, are warranted.

Keywords: Lung; metastases; surgery; oligoprogression; oligometastatic

\footnotetext{
$\wedge$ ORCID: 0000-0003-3690-8582.
} 
Received: 20 August 2021; Accepted: 20 December 2021; Published online: 14 February 2022.

doi: 10.21037/asj-21-81

View this article at: https://dx.doi.org/10.21037/asj-21-81

\section{Introduction}

Malignant neoplasms are acknowledged to spread from their primary site, with frequency varying according to each specific tumor. Since tools for early diagnosis of most tumors are still limited, it is common to detect cancers at advanced stage, when metastatic lesions are observed, with severe impact on management options and prognosis (1). Among distant metastases, pulmonary lesions represent a relevant sub-group, as they are often associated with poor prognosis and usually modify the oncologic strategy, often forcing clinicians to shift from the proposal of radical treatment to palliative approaches; however, pulmonary metastases can still occasionally be managed with local treatments, especially when they are limited in terms of number and size. While the management of pulmonary metastases with local treatments appears appealing, it must be considered that this approach is still uncommon; for instance, fewer than one in 30 patients who have had a colorectal resection subsequently underwent lung resection as it has been observed in big data analyses $(2,3)$. Throughout the last years, a growing interest in the use of local ablative treatments has developed for the management of pulmonary lesions, especially in the case of oligometastatic patients; despite the increasing use of local treatments for the management of patients with advanced tumors, strong available evidence is still relatively limited.

The aim of this narrative review is to provide the oncologist's perspective on the management of pulmonary metastases from solid tumors based on their epidemiology, physiopathology, and therapeutic options, with particular reference to pulmonary lesions detected as oligometastases and occurrence of pulmonary oligoprogression of metastatic cancer. We present the following article in accordance with the Narrative Review reporting checklist (available at https:// asj.amegroups.com/article/view/10.21037/asj-21-81/rc).

\section{Methods}

To support our perspective, we evaluated the available literature in English language published on PubMed, PMC and NLM databases between 2000 and 2021, and we assessed the most relevant international oncology meetings in the same time span. The research keyword combinations included "lung metastasis" or "pulmonary metastasis", which were combined with either "oligometastasis", or "oligoprogression", and with either "surgery" or "radiotherapy". While selecting the suitable literature, we prioritized peer-reviewed, full papers describing metaanalyses and randomized clinical trials, when available. Notably, since colo-rectal cancer represents one of the first solid tumors for which regional approaches to pulmonary metastases were applied, a significant proportion of the collected literature is based on this tumor. Furthermore, the mechanism of metastatization from colo-rectal cancer has been widely studied, and hence provides a good physio-pathological model. Our initial literature search resulted in over 120 indexed full papers, among which we selected the articles which appeared to be more suitable for our subject. The search strategy has been summarized in Table 1 and Table S1.

\section{Epidemiology}

Lungs represent one of the most common sites of metastases from cancer, and it has been observed that $20-45 \%$ of malignant tumors eventually develop pulmonary metastases (4). Common tumors that metastasize to the lung include breast cancer, prostate cancer, colon cancer, sarcoma, bladder cancer, neuroblastoma, Wilm's tumor, as well as primary lung cancer; however, virtually any solid tumor can spread to the lungs occasionally, diagnosis of metastatic cancer can be done by finding pulmonary metastases in absence of a clearly identifiable primary lesion [as cancer of unknown primary (CUP)]. Notably, it has been observed that up to $50 \%$ of patients who die for a malignancy develop pulmonary metastases, as reported in autoptic series $(5,6)$; however, only $15-20 \%$ of patients develop symptoms associated with lung metastases (7).

Interestingly, the histologic nature of lung nodules observed in a population of 228 patients with nonpulmonary primary cancer who underwent pulmonary biopsy was the following: colo-rectal cancer, $25.8 \%$; head and neck cancer, 19.4\%; genitourinary cancer (kidney, ureter, prostate, testes), 14.7\%; gastrointestinal non-colorectal cancer, $10.9 \%$; breast cancer, $10.5 \%$; melanoma, 
Table 1 Search strategy summary

\begin{tabular}{ll}
\hline Items & Specification \\
\hline Date of search & Study search was conducted in July 2021 and repeated during revision in October 2021 \\
Databases and other sources searched & PubMed, PMC and NLM databases; international oncology meetings \\
Search terms used & The research keyword combinations included "lung metastasis" or "pulmonary metastasis", \\
& $\begin{array}{l}\text { which were combined with either "oligometastasis", or "oligoprogression", and with either } \\
\text { "surgery" or "radiotherapy". NCBI-PubMed search terms combination has been reported in } \\
\text { Supplementary Table as an example }\end{array}$ \\
Timeframe & $\begin{array}{l}\text { 2000-2021 } \\
\text { Inclusion and exclusion criteria }\end{array}$ \\
Selection process & $\begin{array}{l}\text { Studies and abstract in English language were included } \\
\text { The search and selection process was initially conducted independently by each author. A } \\
\text { Bottini searched and selected studies involving surgery; F Parisi searched and selected studies } \\
\text { involving radiotherapy; E Cella searched and selected data involving epidemiology and revised } \\
\text { the results of the search involving radiotherapy; G Sacco searched and selected data involving } \\
\text { physiopathology; C Genova revised the results of the search involving surgery, epidemiology } \\
\text { and physiopathology. All the authors revised and approved the final list of suitable studies }\end{array}$ \\
\hline
\end{tabular}

$6.5 \%$; gynecologic cancer (ovarian, endometrial, cervical), $6.1 \%$; other primary sites (sarcoma, thyroid, squamous cell), $6.1 \%(8)$.

\section{Physiopathology}

The process of developing distant metastases is typically connected to intravasation into venous capillaries starting from the primary tumor. Hence, the venous drainage of primary tumor is crucial to determine the "preferred" sites of metastases dissemination. In first place, several homing mechanisms based on molecules including the vascular endothelial growth factor (VEGF), tumor necrosis factor $\alpha(\mathrm{TNF}-\alpha)$, and transforming growth factor $\beta$ (TNF- $\beta$ ) within the pulmonary microenvironment might enhance neoplastic invasion of pulmonary tissue; furthermore, cell adhesion to pulmonary tissue is facilitated by intercellular adhesion molecule 1 (ICAM-1). Additionally, tumor cells that reach blood vessels might preferentially invade pulmonary tissue due to their structure. Indeed, lungs have a wide and complex vascularization, including a dense capillary bed, which is designed to receive large amount of blood for ensuring oxygen exchange; furthermore, lungs include multiple membranes in which migrating neoplastic cells might get entrapped and receive readily available oxygen, as well as nutrients from both bronchial and pulmonary vessels (7).

\section{Pulmonary metastases from colo-rectal cancer}

Colo-rectal cancer is a well representative physiopathological model for the development of pulmonary metastases, due to a particular vascularization. The most frequent initial metastatic site of colo-rectal cancer, accounting for approximately $50 \%$ of patients, is represented by liver, and this occurrence is largely due to the high proportion of blood reaching the liver from colon through the portal vein system. Lung is the second most common site of distant metastases from colo-rectal cancer, and approximately $15 \%$ of patients present with metastatic disease in lungs at diagnosis, due to the rectal venous drainage, divided between portal and systemic circulation (through hemorrhoidal vein plexus) $(9,10)$. This is one of the main factors determining the greater frequency of lung metastases from rectum, compared to colon. Interestingly, a metanalysis shows that the risk of occurrence of lung metastases is higher in left colon cancers [odds ratio (OR) 1.73, $\mathrm{P}<0.017$ ] and rectal cancers (OR 2.80, $\mathrm{P}<0.001)$ compared to right colon cancers (11).

In rectal cancer, the anatomical venous drainage reveals even more crucial role, in order to determinate lung metastases risk. Rectum is approximately $15 \mathrm{~cm}$ in length, from the sacral promontory to the anal verge. Hence, the organ can be divided in lower rectum, 0 to $5 \mathrm{~cm}$ above the pectinate line; mid-rectum, 5.1 to $10 \mathrm{~cm}$ above the pectinate line; and upper rectum, 10.1 to $15 \mathrm{~cm}$ above the pectinate 
line. Rectal venous plexus is responsible of venous drainage of these three anatomical segments, and is composed by the superior rectal vein, confluent into the inferior mesenteric vein and then into the portal system, as well as the middle and inferior rectal veins, which are confluent into the common iliac vein, and then directly into the inferior vena cava. Therefore, a lower rectal tumor can easily develop metastases to the lungs, bypassing the portal system, thus avoiding liver as first site of distant metastasis. Chiang et al. have previously demonstrated that middle and lower rectal cancers present higher risk of developing lung metastases than upper rectal cancers, respectively with a hazard ratio (HR) equal to 1.76 and 3.18. This study demonstrates how crucial is the role of the level of primary rectal cancer, in distant metastases physiopathological process (especially with regard to lung metastases). Data in terms of overall survival (OS) and disease-free survival (DFS) appear strongly connected to the level of rectal cancer:

Indeed, lower rectum cancer was characterized by lower five-year OS and DFS rates $(47.25 \%$ and $44.07 \%$, respectively) compared to mid rectum $(63.46 \%$ and $60.22 \%$, respectively) and upper rectum (73.91\% and $71.87 \%$, respectively) (12).

\section{Clinical presentation and diagnosis}

Pulmonary metastases are usually asymptomatic and hence identified at imaging during staging or follow-up; however, they can occasionally present localized symptoms like cough, dyspnea, or even hemoptysis, which occurs rarely (13).

To evaluate pulmonary metastases, computerized tomography (CT) is an essential method of imaging and it can aid to differentiate non-malignant nodules from malignant lesions. Regular shape, central calcification, and adipose density are more typical of a non-malignant lesion. The sensitivity and specificity of radiologic imaging represent a relevant issue for the management of pulmonary metastases, especially when solitary nodules are identified, and the malignity of these nodules needs to be determined. In a multicenter study enrolling 356 participants, the sensitivity and specificity of contrastenhanced CT scan were $98 \%$ and $58 \%$, respectively (14); in this context, dual time positron emission tomography with fluorodeoxyglucose achieved lower sensitivity (85\%), while specificity was $77 \%$ (15).

Notably, CT scans might also fail to identify some small pulmonary lesions in case of multiple metastases, hence leading to underestimating the number of lesions. In these cases, intraoperative ultrasound (IU) and bimanual palpation by thoracic surgeon can locate pulmonary nodules with high degree of accuracy, although the use of IU might be limited by the presence of air in the lung parenchyma $(16,17)$.

In some cases, particular radiologic patterns of a pulmonary metastasis can suggest the primary tumor it originates from. For instance, calcification can typically occur in a metastatic sarcoma, while pneumothorax is more typical of osteosarcoma and air-space consolidation is often seen in gastrointestinal tumor (18). However, while imaging can assist the characterization of pulmonary metastases, when diagnosis of certainty is mandatory, trans-thoracic or bronchoscopy with biopsy is required.

\section{Oligometastatic disease and therapeutic approaches to pulmonary metastases}

The management of metastatic tumors with pulmonary metastases is usually determined by the primary tumor and typically involves systemic treatments with palliative intent, with varying regimens and results based on the sensitivity to antineoplastic treatments of the involved malignancy.

However, the opportunity to treat metastatic cancer with radical approaches, provided that the number of lesions is limited, should not be underestimate. For instance, a metaanalysis comprising 49 studies with over 2,000 patients affected by advanced non-small cell lung cancer (NSCLC) with a maximum of five metastatic lesions reported a median OS of 19 months and 5 -year OS rate of $23.3 \%$, which was significantly higher than survival data for advanced NSCLC patients with more than five lesions (19). In another metaanalysis, 757 patients with controlled primary NSCLC and ablative treatment to five or less metastatic sites achieved a median OS of 26 months and a 5 -year OS of $29.4 \%$ (20). Hence, the identification of patients whose cancer, albeit metastatic, can be managed with local approaches might translate into a non-negligible survival advantage.

The first definition of oligometastatic disease has been proposed by Hellman and Weichselbaum in 1995 to identify a status between locally confined disease and systemically metastatic disease (21). However, the initially proposed definition includes two different clinical conditions: on one side an initial metastatic disease, on the other side a residual disease, following systemic therapy, due to drug-resistant cells. The above-mentioned situations, while similar for radiologic features, can receive different treatments. Until 2001, the 'oligometastatic' word has been seldom used 
in medical literature, often associated with a situation involving few enough lesions for radical treatments (22). With a wider diffusion and availability of stereotaxic radiotherapy techniques, this word returned to be used by radiation oncologists (23). Neither statistic nor biological basis allow to provide a solid definition for oligometastatic disease (24).

More recently, a new characterization and classification of oligometastatic disease has been suggested, where this term assumes its original meaning as proposed by Hellman, but with distinction between two categories: repeat oligometastatic disease (previous history of metastatic disease) and de-novo oligometastatic disease; furthermore, the latter was subsequently divided into synchronous and metachronous oligometastatic disease. Finally, additional definitions were oligorecurrence (diagnosis of oligometastatic disease during treatment-free interval), oligoprogression (diagnosis of oligometastatic disease during treatment), and oligopersistence (oligometastatic lesion not progressing on current imaging) (25).

The global inconsistency of definition for oligometastatic disease throughout the years has resulted in controversial results across clinical studies. Furthermore, different outcomes have been selected, including curative intent, prolongation of survival, or palliation of symptomatic or potentially dangerous lesions, thus increasing the heterogeneity of settings for loco-regional treatment of pulmonary metastases (26).

\section{Surgical treatment of pulmonary metastases}

The surgical management of pulmonary metastases might be performed in the pursuit of radical treatment, disease prolongation, or symptom palliation. Notably, the available data on pulmonary metastasectomy are relatively limited due to the lack of randomized clinical trials designed to evaluate OS advantage. The most relevant studies involving the surgical management of pulmonary metastases have been reported in Table 2.

The need of radicality determines surgery extension; for lung metastases, sub-lobar wedge excisions are preferred as most of these are hematogenous metastases in contrast to early primary lung cancer $<2 \mathrm{~cm}$, for which anatomical segmentectomies are indicated. Additionally, for the management of pulmonary metastases, in contrast with primary lung cancer, lobectomy is not required for oncologic reasons, although anatomical reasons (such as the size or number of lesions) might make it necessary. Furthermore, a mini-invasive approach compared to open surgery consents a faster after-surgery recovery and a lower impact on quality of life. By contrast, pneumonectomy is rarely considered a suitable approach, especially considering a population consisting of metastatic patients; however, selected cases identified by a multidisciplinary team on an individual basis might still be considered for pneumonectomy (26).

In order to consider a patient eligible for pulmonary metastasectomy, the following criteria have been suggested: (I) the patient is fit for surgery; (II) the primary tumor has been resected or is under control; (III) no extra-thoracic metastases are present or, if present, they can be treated with radical intent; (IV) the thoracic surgeon is able to perform a macroscopic complete resection; (V) an adequate residual pulmonary function is expected after surgery; (VI) no other treatments with reduced morbidity and similar benefits are available (27).

While pulmonary metastases from any solid tumor might virtually benefit from radical surgery, colo-rectal cancer deserves a particular mention, due to the relative frequency of pulmonary metastases and the experience developed in their management compared to other solid malignancies. Indeed, approximately $70 \%$ of patient affected by colo-rectal cancer will develop metastases, including $5-15 \%$ of patients who will develop lung metastases. Notably, metastatic colo-rectal cancer has a dismal prognosis with a 5 -year survival rate equal to $14 \%$, compared to a 5 -year survival rate of $70-90 \%$ for patients affected by localized disease (28). It has been suggested that the lung metastases resection gives more survival chance than chemotherapy alone, anyway surgery's role remains disputable, due to the lack of data available from randomized studies $(29,30)$.

Interestingly, the only randomized study comparing lung metastasectomy with continuous monitoring in colo-rectal cancer (PulMicc trial) was suspended due to slow patient enrolment, thus limiting the available information; however, among the 65 initially enrolled patients, 5-year OS was $38 \%$ in the metastasectomy arm and $29 \%$ in the control arm (31). At the updated analysis with 93 patients, the observed median OS was 3.5 years for patients undergoing metastasectomy and 3.8 years for controls (unadjusted $\mathrm{HR}=0.93 ; 95 \%$ CI: $0.56-1.56$ ), hence reporting longer survival than what has been previously suggested with observation alone (29). Notably, in a health utility analysis of the PulMicc trial, quality of life assessed with EQ-5D$3 \mathrm{~L}$ questionnaire was not improved in the group of patients randomized to metastasectomy compared to controls (32). 
Table 2 Relevant studies involving the use of surgery for pulmonary metastases

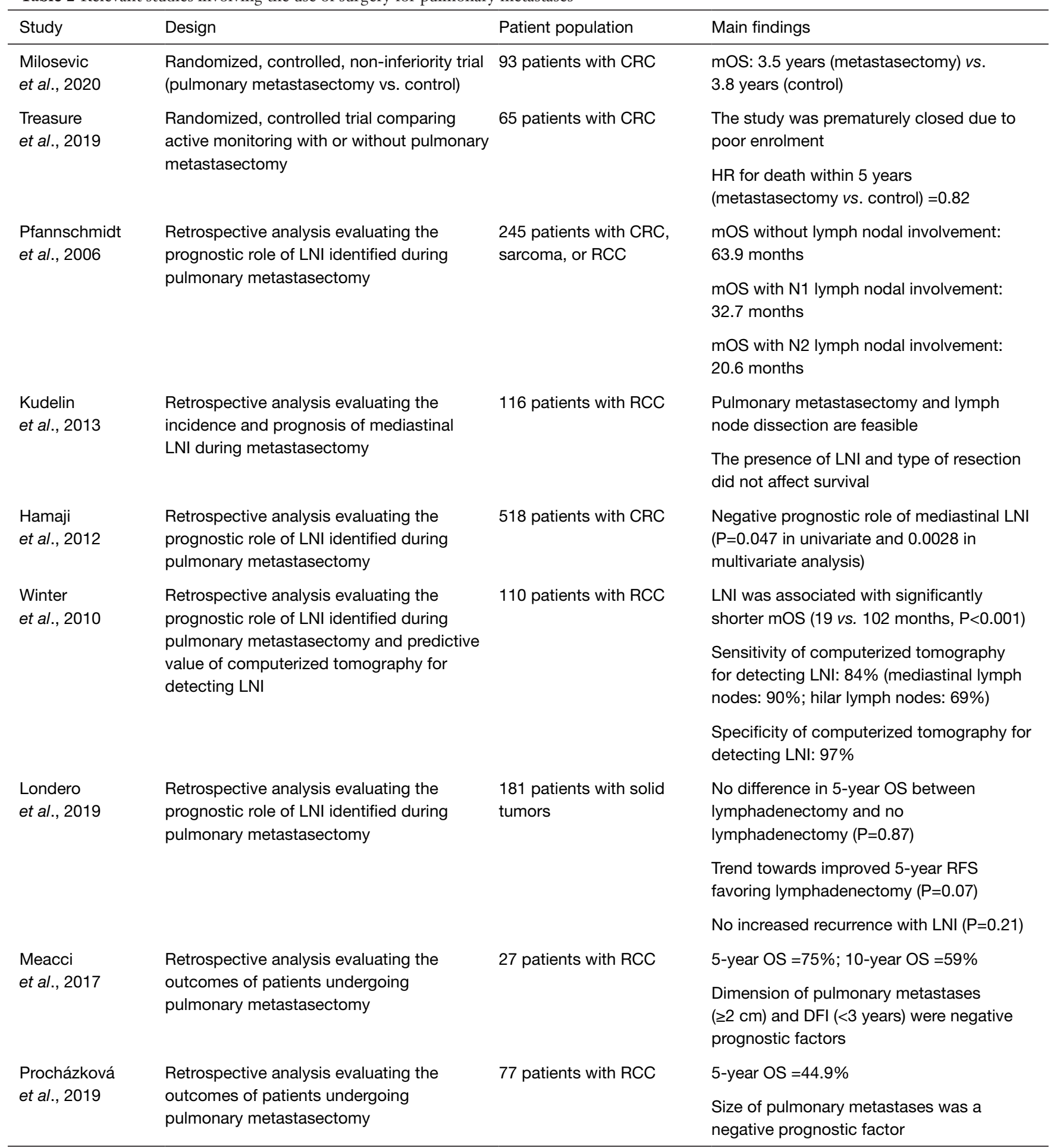

Table 2 (continued) 
Table 2 (continued)

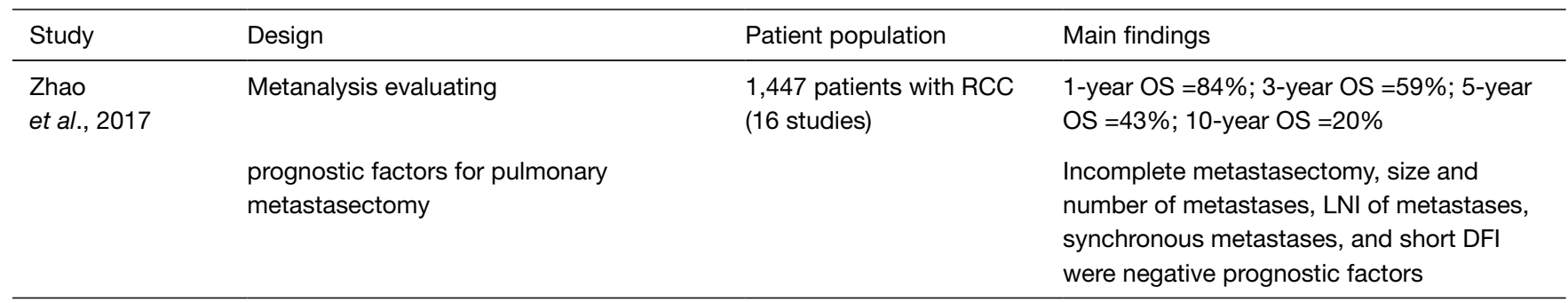

Reference can be found in the text. CRC, colo-rectal cancer; DFI, disease-free interval; LNI, lymph nodal invasion; m, median; OS, overall survival; RCC, renal cell carcinoma; RFS, recurrence-free survival.

Furthermore, the analysis of subsequent treatments after metastasectomy in the population of PulMicc trial suggests that repeated metastasectomies were associated with increased risk of death, while no reduction in terms of use of systemic chemotherapy was observed (24).

Another relevant issue, when addressing surgical treatment of pulmonary metastases, is represented by thoracic lymph nodes; indeed, hilar and mediastinal lymph nodal involvement can be observed in presence of pulmonary metastases and is often considered as negative prognostic factor $(33,34)$. Currently, thoracic lymph node dissection during pulmonary metastasectomy is considered feasible and generally associated with low morbidity and mortality, as reported by Kudelin et al. in a cohort of patients treated with pulmonary metastasectomy and lymph node dissection for oligometastatic renal cell carcinoma (35). However, to date, lymph node dissection is not considered a mandatory procedure during pulmonary metastasectomy (36), in contrast with the approach to primary lung cancer. In 2012, Hamaji and colleagues retrospectively studied the outcomes of 518 patients with colo-rectal cancer who underwent pulmonary metastasectomy, including 199 patients who did not undergo lymph node dissection, 279 patients who underwent lymph node dissection without evidence of lymph nodal disease, and 40 patients who underwent lymph node dissection, in which at least one metastatic lymph node was observed. The presence of lymph nodal metastases was an independent prognostic factor $(\mathrm{P}=0.047)$, and 5 -year OS rate was $48 \%$ in patients with negative lymph nodes and $21 \%$ in patients with metastatic lymph nodes. No survival differences between $\mathrm{N} 1$ level node metastasis and N2 level node metastasis, or between single-station and multi-station metastasis (37). Similarly, Winter and colleagues evaluated a cohort of patients affected by renal cell carcinoma who underwent pulmonary metastasectomy with or without thoracic lymph nodal dissection. Among the patients who underwent lymph nodal dissection, the presence of lymph nodal metastases was associated with shorter survival (19 vs. 102 months; $\mathrm{P}<0.001)$; furthermore, a trend towards improved survival was observed among those patients who underwent metastasectomy plus lymphadenectomy compared to patients who underwent only metastasectomy $(\mathrm{P}=0.068)$ (38).

Finally, Londero and colleagues evaluated the impact of lymph nodal dissection during pulmonary metastasectomy in a population of 181 patients who were treated with pulmonary metastasectomy for different solid tumors, with or without lymphadenectomy. No difference in terms of 5-year OS was observed between patients receiving lymphadenectomy and patients not receiving lymphadenectomy $(\mathrm{P}=0.87)$, while a trend towards improved 5 -year cumulative incidence of recurrence was reported $(\mathrm{P}=0.07)$, favoring lymph nodal dissection. Surprisingly, pathological lymph node involvement did not result in a significant predictor of recurrence $(\mathrm{P}=0.21)$ (39).

\section{Radiation treatment of pulmonary metastases}

For patients unfit for surgery or who refuse it, stereotactic ablative radiotherapy (SABR) is a good option for oligometastases management, particularly for single lung metastases (23). The most relevant studies involving stereotactic radiotherapy in the management of pulmonary metastases have been summarized in Table 3 .

SABR is a method of external radiotherapy focusing a high dose of radiation to an extracranial target lesion in one [defined as stereotactic radiosurgery (SRS)] or few fractions of treatment [defined as stereotactic body radiotherapy (SBRT)], sparing normal tissues (40-42). High doses of focused radiation induce cell death by complex mechanisms, 
Table 3 Disease control rate results of stereotactic body radiotherapy on pulmonary metastases

\begin{tabular}{|c|c|c|c|}
\hline Study & Design & Patient population & Main findings \\
\hline $\begin{array}{l}\text { Rusthoven } \\
\text { et al., } 2009\end{array}$ & $\begin{array}{l}\text { Prospective phase } \mathrm{I} / \mathrm{II} \text { trial evaluating } \\
\text { SBRT for the treatment of patients with a } \\
\text { maximum of } 3 \text { pulmonary metastases }\end{array}$ & $\begin{array}{l}38 \text { patients with pulmonary } \\
\text { metastases }\end{array}$ & $\begin{array}{l}\text { Incidence of grade } \geq 3 \text { toxicity: } 8 \% \\
\text { 1-year local control rate }=100 \% \\
\text { 2-year local control rate }=96 \%\end{array}$ \\
\hline $\begin{array}{l}\text { Brown } \\
\text { et al., } 2008\end{array}$ & $\begin{array}{l}\text { Retrospective analysis evaluating } \\
\text { image-guided robotic stereotactic } \\
\text { radiosurgery for pulmonary lesion }\end{array}$ & $\begin{array}{l}35 \text { patients with } \\
\text { histologically-proven } \\
\text { pulmonary metastases }\end{array}$ & $\begin{array}{l}\text { Local control rate }=71 \%(25 \mathrm{CR}, 16 \mathrm{PR}, 7 \mathrm{SD}) \\
\text { Only one patient experienced grade } \geq 3 \\
\text { pulmonary toxicity }\end{array}$ \\
\hline $\begin{array}{l}\text { Okunieff } \\
\text { et al., } 2006\end{array}$ & $\begin{array}{l}\text { Prospective study evaluating the } \\
\text { outcomes of patients treated with } \\
\text { SBRT either treated with curative intent } \\
\text { (maximum } 5 \text { lesions) or palliative } \\
\text { intent ( }>5 \text { lesions) }\end{array}$ & $\begin{array}{l}50 \text { patients with pulmonary } \\
\text { metastases }\end{array}$ & $\begin{array}{l}\text { Local control rate }=83 \% \\
\text { mOS }=23.4 \text { months (curative intent) } \\
\text { 1-year PFS }=25 \% \text { (curative intent) } \\
2 \text {-year PFS }=16 \% \text { (curative intent) }\end{array}$ \\
\hline $\begin{array}{l}\text { Owen } \\
\text { et al., } 2015\end{array}$ & $\begin{array}{l}\text { Prospective study evaluating the } \\
\text { outcomes of patients treated with } \\
\text { multiple courses of SBRT for multiple } \\
\text { and recurrent pulmonary nodules }\end{array}$ & $\begin{array}{l}63 \text { patients with } \\
\text { metasynchronous and } \\
\text { synchronous lung nodules }\end{array}$ & $\begin{array}{l}\text { SBRT-specific OS }=35.7 \text { months } \\
\text { SBRT-specific PFS }=10.7 \text { months } \\
\text { Acute toxicity (mostly grade } 1-2 \text { fatigue) }=51 \% \\
\text { Only one patient experienced grade } \geq 3 \\
\text { pulmonary toxicity }\end{array}$ \\
\hline $\begin{array}{l}\text { Palma } \\
\text { et al., } 2020\end{array}$ & $\begin{array}{l}\text { Phase II, randomized controlled trial } \\
\text { evaluating SABR plus } S O C \text { vs. } \\
\text { palliative SOC treatments }\end{array}$ & $\begin{array}{l}99 \text { patients with } 1-5 \\
\text { pulmonary metastases (and } \\
\text { controlled primary tumor) }\end{array}$ & $\begin{array}{l}\text { mOS }=50 \text { vs. } 28 \text { months }(P=0.006) \\
5 \text {-year } \mathrm{OS}=42.3 \% \text { vs. } 17.7 \%(P=0.006) \\
5 \text {-year } \mathrm{PFS}=17.3 \% \text { vs. } 0 \%(\mathrm{P}=0.001) \\
\text { Overall long-term lesional control rate }=63 \% \\
\text { vs. } 46 \%(\mathrm{P}=0.039)\end{array}$ \\
\hline
\end{tabular}

CR, complete response; m, median; OS, overall survival; PFS, progression-free survival; PR, partial response; SABR, stereotactic ablative radiotherapy; SBRT, stereotactic body radiotherapy; $\mathrm{SD}$, stable disease; $\mathrm{SOC}$, standard of care. 
including damage to the DNA and endothelium with microcirculation dysfunction.

Throughout the years, SABR has been used for the radical treatment of single lung lesions in early stage NSCLC, based on data from phase II studies which showed high rates of local disease control with SABR in patients not fit for radical lung resection with stage I NSCLC (43-48); these benefits are comparable to surgery and result in increased OS compared with conventional radiotherapy (49-51), with acceptable toxicity in patients with pulmonary comorbidities and reduced pulmonary function, including elderly patients $(52,53)$.

Subsequently, the use of stereotactic radiotherapy has also extended to the treatment of lung metastases, alone or in association with systemic therapy. Several retrospective and prospective trials shown a 1-year local control rate up to $95 \%$ in oligometastatic disease treated with radiotherapy (46,54-59). Emerging relevance of this approach was observed especially in treatment of lung metastases from colo-rectal cancer. More specifically, in a study including 65 patients treated with SBRT for lung metastases, while median PFS was 5.7 months, median OS was reasonably long (20.3 months); in this study, negative prognostic factors were the presence of extra-pulmonary and extrahepatic lesions at stage IV diagnosis or at SBRT (60).

In a randomized, phase II trial (SABR-COMET), 99 patients with a controlled primary malignancy and up to 5 metastases, of which $43 \%$ had lung lesions, potentially treatable with SABR were randomized (1:2) to palliative standard of care (SOC) alone or SOC plus SABR; in this trial, SOC-SABR was associated with increased 5 -year OS rate over SOC alone ( $42.3 \%$ vs. $17.7 \% ; \mathrm{P}=0.006)$ with no detrimental effect on quality of life or novel emerging toxicities. Further, a significant difference was shown in lesion control rate after SABR, according to site of metastasis, which reached $51 \%$ for lung lesions (61).

The feasibility of SABR was also investigated for recurrent lung nodules (synchronous or metachronous) emerging in patients who had received prior mediastinum or chest high external dose radiation to mediastinum or chest. In a review, the results of 7 studies involving re-irradiation (with SBRT) of thoracic recurrencies from lung cancer, with a total of 140 patients, were summarized; globally, re-irradiation with a median dose of 40-80 Gy was well tolerated, with local control accounting for $65-92 \%$ (62).

Owen et al. showed local disease-control rate of $99 \%$ at 24 months in a population of 63 patients treated with multiple courses of SABR for a total of 128 metachronous or synchronous lung metastases from different tumors, with a high proportion of lung cancers; 18 out of 63 patients had previously received chest radiation. Median PFS and OS were 10.7 and 35.7 months. Notably, the treatment was well tolerated: in particular, most common early and delayed symptoms were grade 1 or 2 fatigue and dyspnea, while only three patients developed high grade dyspnea, none of whom had previously received chest radiotherapy (63).

Notably, the risk of relapse in patients treated with stereotactic radiotherapy on single or multiple secondary lesions appears to be related to the dose of radiation received; indeed, several studies addressed the efficacy of different models of fractionation and dose of SABR, according to volume, size, number of target lesions and original primary tumor $(55,64)$. In a systematic review by Siva et al., no statistically significant difference emerged between single and multifractionated SABR for lung metastases, either in terms of toxicity or efficacy (65). Moreover, based on data from retrospective studies and randomized trials on treatment of early-stage lung cancer, the ablative effect of stereotactic radiotherapy is achieved at more than $90 \%$ of cases with effective biological dose (BED) greater than $100 \mathrm{~Gy}$, irrespective of fractionation approaches $(66,67)$.

With regard to comparisons between surgery and radiotherapy for pulmonary metastases, the currently available evidence is mostly based on retrospective data. In a retrospective study including 170 patients with oligometastatic colo-rectal cancer, of which 142 underwent pulmonary metastasectomy and 28 SBRT on pulmonary lesions, 1-year OS rate and 2-year OS rate were similar between surgery and radiation therapy ( $96 \%$ vs. $89 \%$ and $82 \%$ vs. $77 \%$, respectively; $\mathrm{P}=0.134)(68)$. In a systematic review of literature conducted by Londero et al. including 61 studies on surgery and 18 studies on SBRT, no significant difference between surgery and SBRT for treatment of lung metastases was reported in terms of short-term survival; more specifically, 1-year OS was $71-96 \%$ with surgery and $74-94.5 \%$ with SBRT. With regard to long-term survival, surgery appears to achieve greater benefit compared to radiotherapy, although the authors state that only few reported articles included prolonged follow-up and that this observation might be limited due to the tendency to use SBRT in patients excluded from surgery due to poor performance status or patient's refusal, possibly with an impact on outcomes (69).

\section{Other local approaches to pulmonary metastases}

While surgery and SBRT represent the main local 
therapeutic approaches to pulmonary metastases, other techniques designed to treat these lesions with radical intent are gaining increasing relevance.

One of these approaches is radiofrequency ablation (RFA), which destroys cancer cells by applying thermal energy under imaging guidance; compared to other organs, the lung is more sensitive to radiofrequency (70). In a study including 566 patients with lung metastases from different primary tumors, treatment with RFA achieved 3 -year OS equal to $67.7 \%$ and 3 -year PFS equal to $16.4 \%$. Fifty-three percent of the enrolled patients had a single metastasis and only $4 \%$ had more than 5 lesions; in $75 \%$ of case metastases were bilateral and most of lesions (68\%) were $2-3 \mathrm{~cm}$, with overall median diameter of $15 \mathrm{~mm}$. Among patients affected by colo-rectal cancer (34\%), the size of single metastases $>2 \mathrm{~cm}(\mathrm{HR}=2.10, \mathrm{P}=0.0027)$, the number of secondary lesions $>3(\mathrm{HR}=1.86, \mathrm{P}=0.011)$ were significantly associated with worse survival. Notably, RFA was successfully repeated on 136 patients, after local failure of the original RFA or for disease progression in other sites, up to four times (71). Several additional retrospective studies on the efficacy of RFA, especially on metastases from colo-rectal cancer, demonstrated favorable local control disease and safety profile, especially in case of small lesions $(72,73)$. These data support the role of RFA as a feasible alternative to surgery or SBRT.

Another local procedure with encouraging, albeit limited data, is cryoablation; this approach is based on application, under general anesthesia or conscious sedation, of several freeze-thaw cycles to the target tissue, guided by CT imaging (74). In the ECLIPSE trial, de Baere and colleagues evaluated the feasibility and the safety of cryoablation in a population of 40 patients with lung metastases from various solid tumors, most of them (40\%) being affected by colorectal cancer. In $20 \%$ of cases, lung metastases were bilateral and no larger than $3.5 \mathrm{~cm}$; moreover, $18 \%$ of the enrolled patients received systemic chemotherapy concurrently with cryoablation or after the procedure, but none received radiation therapy to target lesions after cryoablation. The study population achieved 6-month disease control rate (DCR) equal to $96.6 \%$ and 12 -month DCR equal to $94.2 \%$, with preserved quality of life (75). The updated follow-up of ECLIPSE showed a 5-year local tumor control rate equal to $75 \%$, while 5 -year disease-specific survival rate and 5 -year OS rate were $55.3 \%$ and $46.7 \%$, respectively (76).

Finally, albeit still experimental, the use of isolated lung perfusion has been evaluated in a prospective, singlearm phase II trial, in which 107 patients with pulmonary metastases from colo-rectal carcinoma, osteosarcoma, and soft-tissue sarcoma underwent pulmonary metastasectomy combined with isolated lung perfusion with melphalan $(45 \mathrm{mg})$ at $37^{\circ} \mathrm{C}$. The approach was well tolerated with low morbidity and absence of long-term lung toxicity. With regard to efficacy, 5-year DFS rate and pulmonary PFS rate were $26 \%$ and $44 \%$ for colo-rectal carcinoma and $29 \%$ and $63 \%$ for sarcoma, respectively; 5 -year OS was $57 \%$ for colorectal carcinoma and $28 \%$ for sarcoma (77).

\section{Combination of loco-regional and systemic treatments for pulmonary metastases}

While the management of patients with multiple metastatic lesions is primarily based on palliative systemic treatments, the benefit of systemic treatments in association with local ablation of oligometastatic disease is far less defined.

In 2002, Downey et al. published the results of a phase II trial including 23 patients with NSCLC and a solitary synchronous metastatic site, who were treated with perioperative chemotherapy with mitomycin, vinblastine, and cisplatin (three cycles before resection and two postoperative cycles); according to the authors, the small patient population did not achieve improved outcomes compared to historical controls who underwent surgery alone (78).

More recently, in a study including 420 patients who underwent pulmonary metastasectomy, of whom 151 (36\%) received peri-operative chemotherapy (mostly post-operative). While in the global population postoperative chemotherapy was not associated with improved OS (HR =0.93), an advantage was observed in the subgroup of patients who had not previously received adjuvant chemotherapy for colo-rectal cancer $(\mathrm{HR}=0.50)(79)$. In another retrospective study, the outcomes of 100 patients who underwent pulmonary metastasectomy for oligo-metastatic colo-rectal cancer were analyzed. In this population, the use of adjuvant chemotherapy after metastasectomy strongly affected OS compared to surgery alone $(\mathrm{HR}=0.35 ; \mathrm{P}=0.014)(80)$.

In 2019, Gomez and colleagues published the results of a randomized, phase II study enrolling patients affected by advanced NSCLC with three or fewer metastases and no progression after at least 3 months after completion of firstline induction chemotherapy. The enrolled patients were randomized (1:1) to maintenance/observation (based on the employed first-line) $v s$. local consolidative therapy to all active disease sites; local treatments included surgery, radiation, or a combination of both. The study was prematurely 
closed after the treatment of 49 patients, as an interim analysis planned by the Data Safety Monitoring Committee demonstrated a clinically relevant and statistically significant advantage in terms of PFS (the primary endpoint) with local consolidative therapy over maintenance/observation (11.9 vs. 3.9 months; $\mathrm{P}=0.0054)$ (81). At the updated follow-up time of over 36 months, the PFS benefit was maintained (14.2 vs. 4.4 months; $\mathrm{P}=0.022$ ), and the local consolidative therapy arm achieved also a significant OS advantage over maintenance/ observation (41.2 vs. 17.0 months; $\mathrm{P}=0.017$ ), thus supporting the use of local approaches when disease control is achieved by systemic chemotherapy in NSCLC (82).

Since novel systemic treatments, including targeted agents and immune checkpoint inhibitors, have revolutionized the management of multiple advanced neoplasms, there is growing interest on combination approaches to oligoprogressive disease with the aim of improving the effect of these systemic treatments with local ablative procedures. For instance, radiation appears to prolong the duration of delivery of tyrosine kinase inhibitors (TKIs). More specifically, in a study of ablative treatments in association with TKIs for NSCLC, patients receiving crizotinib for $A L K$-rearranged NSCLC $(\mathrm{n}=38)$ or erlotinib for $E G F R$ mutant NSCLC $(\mathrm{n}=27)$ were treated with local ablative treatments (either surgery or radiotherapy), resulting in approximately 6 months of additional disease control (83). In a single-arm, phase II study, 24 patients received erlotinib and concurrent SBRT for oligoprogressive metastatic NSCLC after a first-line based on platinum-derivates. The combined treatment resulted in median PFS equal to 14.7 months and median OS equal to 20.4 months, which were remarkably high compared to historical controls in the same setting (84). A large area of research focuses on radiotherapy-immunotherapy association, since preclinical and clinical evidence reports pro-immunogenic impact on tumor cells caused by high doses of radiotherapy. More specifically, it has been observed that radiation on a specific neoplastic lesion might stimulate the release tumor-related antigens and pro-immunogenic factors, which ultimately stimulate the activity of lymphocytes, enhancing the effect of immune checkpoint inhibitors on other metastases distant from the irradiated lesion (abscopal effect) (85). Several studies designed to assess the clinical relevance of abscopal effect are currently ongoing (86-89).

\section{Discussion}

The management of metastatic malignancies represents a daily challenge for medical oncologists. On one hand, the detection of synchronous distant metastases might preclude the option of curative treatments for the primary tumor, even when it is technically resectable; on the other hand, the development of metachronous metastases during followup after surgery for the primary neoplasm dramatically changes the perspective of a patient who was previously considered as cured. In both situations, the occurrence of distant metastases impacts the survival of each patient and determines the subsequent treatments (1).

While in most cases metastatic disease can only be treated with systemic palliative treatments, there are some instances in which such lesions can be radically treated, potentially making the patient free from detectable disease despite advanced stage. Among distant metastases, pulmonary lesions are especially relevant due to their frequency in multiple solid malignancies and the possibility to treat such lesions with loco-regional treatments. In this context, colo-rectal cancer is an effective model for the ablative treatment of distant metastases, with particular reference to pulmonary lesions, as well as hepatic lesions; however, the surgical or radiotherapeutic approach to pulmonary metastases is gaining relevance in multiple solid malignancies. The first issue when approaching pulmonary metastases with loco-regional treatments is defining "oligometastatic disease"; indeed, previous publications have put different limits in terms of the maximum number of "oligometastatic" pulmonary lesions (either three or five lesions) (7), while other researchers have focused on the pattern of presentation of oligometastases (25). Despite inconsistencies among different clinical studies, the limit of five lesions can be accepted for oligometastatic state, provided that all the lesions can be radically treated. Furthermore, it has been generally observed that the number of resected pulmonary metastases was generally associated with prognosis, suggesting that for patients with numerous, albeit technically operable lesions, locoregional treatment might not be the best approach. A similar observation has been done with regard to the size of metastatic lesions; notably, the observation of worse prognosis in presence of lesions with increased diameter might be possibly more associated with the presence of more circulating tumor cells or micrometastases, rather than the technical difficulty to radically remove the known lesions, as none of the studies showing the effect of the size reported issues of incomplete metastasectomy $(90,91)$.

With regard to the use of systemic therapy administered in a peri-metastasectomy setting, the most robust data 
derive from retrospective data involving colo-rectal cancer, although prospective clinical trials with small patient populations have been published. In this context, while the available evidence is not unequivocally consistent, it appears that systemic chemotherapy might improve the outcomes in terms of survival of treated patients, especially when adjuvant chemotherapy for the primary cancer was not previously administered (79); similarly, the use of induction chemotherapy for advanced NSCLC followed by local radical approaches in case of persistent disease control translated into survival benefit $(81,82)$. The occurrence of synergy between systemic and local treatments might be explained with the combination of removal of macroscopic lesions and effect on microscopic disease, which might be present in form of micro-metastases or circulating tumor cells; indeed, the principle of adjuvant chemotherapy lies in the clearance of microscopic disease after the primary cancer is locally resected, and the same principle is easily applicable to oligometastatic disease, as in this case circulating tumor cells spreading from the primary neoplasm are not only suspected (as is the case of adjuvant therapy), but are demonstrated by the presence of oligometastases in first place. Currently, available data are mostly based on chemotherapy; however, novel therapies such as targeted agents and immune checkpoint inhibitors have become the cornerstone for the treatment for various solid tumors and are also becoming increasingly employed in the adjuvant and neoadjuvant setting; hence, the magnitude of benefit achieved by novel antineoplastic treatments after metastasectomy has yet to be fully elucidated $(92,93)$. Notably, some antineoplastic agents exert an antiangiogenic action by inhibiting the VEGF pathway, either as exclusive antineoplastic effect (e.g., bevacizumab), or as part of a multi-targeted action (e.g., sunitinib, nintedanib) $(94,95)$; since the development of metastases, and especially pulmonary lesions, is strongly associated with neoangiogenesis (9), the use of such agents in combination with loco-regional treatments might result particularly effective.

In addition, a concept worth mentioning is represented by oligoprogression, which should not be confounded with oligometastatic disease; indeed, oligoprogressive disease includes situations in which the tumor is not limited to a single or few metastatic lesions, but the failure of the initial systemic treatment is represented by a limited number of sites, potentially suitable for loco-regional approaches (96). Notably, this occurrence has been largely described in oncogenic-driven tumors, such as EGFR-mutant NSCLC
$(83,97)$. The reason for this occurrence might lie in the particular mechanisms of acquired resistance to targeted agents, which is based on the development and selection of clones with novel acquired genic alterations enabling the neoplastic cells to survive targeted agents (96). In this context, the development of new isolated lesions in a disease which is otherwise under control during systemic treatment creates a good opportunity for loco-regional approaches including surgery and radiation therapy, as such treatments might succeed in ablating a lesion characterized by cell clones resistant to the systemic therapy, hence potentially delaying the occurrence of actual, systemic progression requiring the switch to a subsequent line of therapy. Obviously, in contrast with oligometastatic disease, the aim of loco-regional treatments in oligoprogressive disease is not the potential cure, but rather prolongation of progression-free survival or time to treatment failure. In this setting, radiation therapy is gaining increasing relevance, possibly due to the easier accessibility to metastatic patients compared to surgery, as well as the opportunity to rapidly resume systemic therapy, in contrast with surgery, which may require a non-negligible withdrawal of systemic treatments; furthermore, potential interactions with systemic agents such as immune checkpoint inhibition and radiation therapy have been observed, including abscopal effect $(85,96)$.

In conclusion, while the currently available evidence involving the use of radical approaches (either surgery or radiation therapy) is mostly based on retrospective data, with limited meta-analyses and randomized trials, the acquired knowledge suggests that oligometastatic disease might be radically treated, provided that the primary tumor is already controlled; this approach can result in survival increase and eventually cure, although more robust predictive factors are needed. Similarly, even in a context of metastatic disease not amenable to cure, the occurrence of oligoprogression can be treated with local approaches (in this case, preferably radiation therapy). Finally, while systemic antineoplastic treatments are pivotal in metastatic disease and oligoprogressive disease, their role in oligometastatic state is less defined, although benefits in terms of survival have been observed in multiple studies. The dramatic evolution of systemic treatments observed in the advanced palliative setting might translate into clinical benefit also in the oligometastatic setting, eventually leading to an increase of potentially curable patients in spite of the occurrence of pulmonary metastases. The development of ad hoc clinical research, with specific 
regard to prospective studies designed to fully disclose the interactions and synergies between systemic treatments (and especially novel approaches such as immunotherapy or targeted therapies) and local ablative treatments such as surgery and radiation therapy even in advanced cancer are warranted; however, we must take into account the potential difficulties of designing controlled clinical trials in which patients are randomized to receive ablative treatments for oligometastases or systemic treatment alone, due to accrual and ethical issues. In this context, oligoprogressive disease is a more easily approachable setting for prospective studies, which will eventually provide pivotal insights on the combinations of systemic and local approaches in advanced solid tumors with distant metastases including pulmonary lesions.

\section{Acknowledgments}

The authors wish to thank the Italian Ministry of Health (5x1000 funds) and Bristol-Myers-Squibb (No. CA-209828 ) for grants supporting translational research on immune checkpoint inhibitors in advanced non-small cell lung cancer.

Funding: None.

\section{Footnote}

Provenance and Peer Review: This article was commissioned by the Guest Editors (Davide Tosi, Alessandro Palleschi and Paolo Mendogni) for the series "Management and Treatment of Lung Metastases" published in AME Surgical fournal. The article has undergone external peer review.

Reporting Checklist: The authors have completed the Narrative Review reporting checklist. Available at https:// asj.amegroups.com/article/view/10.21037/asj-21-81/rc

Peer Review File: Available at https://asj.amegroups.com/ article/view/10.21037/asj-21-81/prf

Conflicts of Interest: All authors have completed the ICMJE uniform disclosure form (available at https://asj.amegroups. com/article/view/10.21037/asj-21-81/coif). The series "Management and Treatment of Lung Metastases" was commissioned by the editorial office without any funding or sponsorship. CG declares the following disclosures: (I) Honoraria from Astra Zeneca, Boehringer Ingelheim, Bristol-Myers-Squibb, Merck Sharp Dohme, Roche;
(II) Participation in advisory boards for Astra Zeneca, Boehringer Ingelheim, Bristol-Myers-Squibb, Merck Sharp Dohme, Roche, Takeda; (III) Research grants from the Italian Ministry of Health (5x1000 funds) and from BristolMyers-Squibb (No. CA209-828). The authors have no other conflicts of interest to declare.

Ethical Statement: The authors are accountable for all aspects of the work in ensuring that questions related to the accuracy or integrity of any part of the work are appropriately investigated and resolved.

Open Access Statement: This is an Open Access article distributed in accordance with the Creative Commons Attribution-NonCommercial-NoDerivs 4.0 International License (CC BY-NC-ND 4.0), which permits the noncommercial replication and distribution of the article with the strict proviso that no changes or edits are made and the original work is properly cited (including links to both the formal publication through the relevant DOI and the license). See: https://creativecommons.org/licenses/by-nc-nd/4.0/.

\section{References}

1. Surveillance, Epidemiology, and End Results Program [Internet]. SEER. [cited $2021 \mathrm{Jul}$ 31]. Available online: https://seer.cancer.gov/index.html

2. Fenton HM, Finan PJ, Milton R, et al. National variation in pulmonary metastasectomy for colorectal cancer. Colorectal Dis 2021;23:1306-16.

3. Embún R, Fiorentino F, Treasure T, et al. Pulmonary metastasectomy in colorectal cancer: a prospective study of demography and clinical characteristics of 543 patients in the Spanish colorectal metastasectomy registry (GECMPCCR). BMJ Open 2013;3:002787.

4. Zhao X, Wen X, Wei W, et al. Clinical characteristics and prognoses of patients treated surgically for metastatic lung tumors. Oncotarget 2017;8:46491-7.

5. Putnam JB Jr. New and evolving treatment methods for pulmonary metastases. Semin Thorac Cardiovasc Surg 2002;14:49-56.

6. Hirakata K, Nakata H, Nakagawa T. CT of pulmonary metastases with pathological correlation. Semin Ultrasound CT MR 1995;16:379-94.

7. Gerull WD, Puri V, Kozower BD. The epidemiology and biology of pulmonary metastases. J Thorac Dis 2021;13:2585-9.

8. Caparica R, Mak MP, Rocha CH, et al. Pulmonary 
Nodules in Patients With Nonpulmonary Cancer: Not Always Metastases. J Glob Oncol 2016;2:138-44.

9. Wong SY, Hynes RO. Lymphatic or Hematogenous Dissemination: How Does a Metastatic Tumor Cell Decide? Cell Cycle 2006;5:812-7.

10. Vatandoust S, Price TJ, Karapetis CS. Colorectal cancer: Metastases to a single organ. World J Gastroenterol 2015;21:11767-76.

11. Mitry E, Guiu B, Cosconea S, et al. Epidemiology, management and prognosis of colorectal cancer with lung metastases: a 30-year population-based study. Gut 2010;59:1383-8.

12. Chiang JM, Hsieh PS, Chen JS, et al. Rectal cancer level significantly affects rates and patterns of distant metastases among rectal cancer patients post curative-intent surgery without neoadjuvant therapy. World J Surg Oncol 2014;12:197.

13. Gaillard F. Pulmonary metastases I Radiology Reference Article I Radiopaedia.org [Internet]. Radiopaedia. [cited 2021 Nov 30]. Available online: https://radiopaedia.org/ articles/pulmonary-metastases

14. Swensen SJ, Viggiano RW, Midthun DE, et al. Lung nodule enhancement at CT: multicenter study. Radiology 2000;214:73-80.

15. Gould MK, Donington J, Lynch WR, et al. Evaluation of Individuals With Pulmonary Nodules: When Is It Lung Cancer? Chest 2013;143:e93S-e120S.

16. Huang YH, Chen KC, Chen JS. Ultrasound for intraoperative localization of lung nodules during thoracoscopic surgery. Ann Transl Med 2019;7:37.

17. Yenigün BM, Yüksel C, Kahya Y, et al. Effectiveness of intraoperative bimanual palpation in metastatic tumors of lung. Turk Gogus Kalp Damar Cerrahisi Derg 2020;28:662-8.

18. Seo JB, Im JG, Goo JM, et al. Atypical pulmonary metastases: spectrum of radiologic findings. Radiographics 2001;21:403-17.

19. Ashworth A, Rodrigues G, Boldt G, et al. Is there an oligometastatic state in non-small cell lung cancer? A systematic review of the literature. Lung Cancer 2013;82:197-203.

20. Ashworth AB, Senan S, Palma DA, et al. An individual patient data metaanalysis of outcomes and prognostic factors after treatment of oligometastatic non-small-cell lung cancer. Clin Lung Cancer 2014;15:346-55.

21. Hellman S, Weichselbaum RR. Oligometastases. J Clin Oncol 1995;13:8-10.

22. Treasure T. Oligometastatic cancer: an entity, a useful concept, or a therapeutic opportunity? J R Soc Med 2012;105:242-6.

23. Lewis SL, Porceddu S, Nakamura N, et al. Definitive Stereotactic Body Radiotherapy (SBRT) for Extracranial Oligometastases: An International Survey of $>1000$ Radiation Oncologists. Am J Clin Oncol 2017;40:418-22.

24. Treasure T, Farewell V, Macbeth F, et al. The Pulmonary Metastasectomy in Colorectal Cancer (PulMiCC) burden of care study: Analysis of local treatments for lung metastases and systemic chemotherapy in 220 patients in the PulMiCC cohort. Colorectal Dis 2021;23:2911-22.

25. Guckenberger M, Lievens Y, Bouma AB, et al. Characterisation and classification of oligometastatic disease: a European Society for Radiotherapy and Oncology and European Organisation for Research and Treatment of Cancer consensus recommendation. Lancet Oncol 2020;21:e18-28.

26. Kaneda H, Saito Y. Oligometastases: Defined by prognosis and evaluated by cure. Cancer Treatment Communications 2015;3:1-6.

27. Sudarshan M, Murthy SC. Current Indications for Pulmonary Metastasectomy. Surg Oncol Clin N Am 2020;29:673-83.

28. Wang J, Li S, Liu Y, et al. Metastatic patterns and survival outcomes in patients with stage IV colon cancer: A population-based analysis. Cancer Med 2020;9:361-73.

29. Milosevic M, Edwards J, Tsang D, et al. Pulmonary Metastasectomy in Colorectal Cancer: updated analysis of 93 randomized patients - control survival is much better than previously assumed. Colorectal Dis 2020;22:1314-24.

30. Kim HK, Cho JH, Lee HY, et al. Pulmonary metastasectomy for colorectal cancer: how many nodules, how many times? World J Gastroenterol 2014;20:6133-45.

31. Treasure T, Farewell V, Macbeth F, et al. Pulmonary Metastasectomy versus Continued Active Monitoring in Colorectal Cancer (PulMiCC): a multicentre randomised clinical trial. Trials 2019;20:718.

32. Brew-Graves C, Farewell V, Monson K, et al. Pulmonary metastasectomy in colorectal cancer: health utility scores by EQ-5D-3L in a randomized controlled trial show no benefit from lung metastasectomy. Colorectal Dis 2021;23:200-5.

33. Handy JR, Bremner RM, Crocenzi TS, et al. Expert Consensus Document on Pulmonary Metastasectomy. Ann Thorac Surg 2019;107:631-49.

34. Pfannschmidt J, Klode J, Muley T, et al. Nodal involvement at the time of pulmonary metastasectomy: 
experiences in 245 patients. Ann Thorac Surg 2006;81:448-54.

35. Kudelin N, Bölükbas S, Eberlein M, et al. Metastasectomy with standardized lymph node dissection for metastatic renal cell carcinoma: an 11-year single-center experience. Ann Thorac Surg 2013;96:265-70: discussion 270-1.

36. Sihag S, Muniappan A. Lymph Node Dissection and Pulmonary Metastasectomy. Thorac Surg Clin 2016;26:315-23.

37. Hamaji M, Cassivi SD, Shen KR, et al. Is lymph node dissection required in pulmonary metastasectomy for colorectal adenocarcinoma? Ann Thorac Surg 2012;94:1796-800.

38. Winter H, Meimarakis G, Angele MK, et al. Tumor infiltrated hilar and mediastinal lymph nodes are an independent prognostic factor for decreased survival after pulmonary metastasectomy in patients with renal cell carcinoma. J Urol 2010;184:1888-94.

39. Londero F, Morelli A, Parise O, et al. Lymphadenectomy during pulmonary metastasectomy: Impact on survival and recurrence. J Surg Oncol 2019;120:768-78.

40. Uematsu M, Shioda A, Tahara K, et al. Focal, high dose, and fractionated modified stereotactic radiation therapy for lung carcinoma patients: a preliminary experience. Cancer 1998;82:1062-70.

41. Wulf J, Hädinger U, Oppitz U, et al. Stereotactic radiotherapy of extracranial targets: CT-simulation and accuracy of treatment in the stereotactic body frame. Radiother Oncol 2000;57:225-36.

42. Benedict SH, Yenice KM, Followill D, et al. Stereotactic body radiation therapy: the report of AAPM Task Group 101. Med Phys 2010;37:4078-101.

43. Nagata Y, Takayama K, Matsuo Y, et al. Clinical outcomes of a phase I/II study of 48 Gy of stereotactic body radiotherapy in 4 fractions for primary lung cancer using a stereotactic body frame. Int J Radiat Oncol Biol Phys 2005;63:1427-31.

44. Baumann P, Nyman J, Hoyer M, et al. Outcome in a prospective phase II trial of medically inoperable stage I non-small-cell lung cancer patients treated with stereotactic body radiotherapy. J Clin Oncol 2009;27:3290-6.

45. Fakiris AJ, McGarry RC, Yiannoutsos CT, et al. Stereotactic body radiation therapy for early-stage non-small-cell lung carcinoma: four-year results of a prospective phase II study. Int J Radiat Oncol Biol Phys 2009;75:677-82.

46. Ricardi U, Filippi AR, Guarneri A, et al. Stereotactic body radiation therapy for early stage non-small cell lung cancer: results of a prospective trial. Lung Cancer 2010;68:72-7.

47. Timmerman R, Paulus R, Galvin J, et al. Stereotactic body radiation therapy for inoperable early stage lung cancer. JAMA 2010;303:1070-6.

48. Bral S, Gevaert T, Linthout N, et al. Prospective, riskadapted strategy of stereotactic body radiotherapy for early-stage non-small-cell lung cancer: results of a Phase II trial. Int J Radiat Oncol Biol Phys 2011;80:1343-9.

49. Crabtree TD, Denlinger CE, Meyers BF, et al. Stereotactic body radiation therapy versus surgical resection for stage I non-small cell lung cancer. J Thorac Cardiovasc Surg 2010;140:377-86.

50. Rowell NP, Williams CJ. Radical radiotherapy for stage I/ II non-small cell lung cancer in patients not sufficiently fit for or declining surgery (medically inoperable): a systematic review. Thorax 2001;56:628-38.

51. Grutters JP, Kessels AG, Pijls-Johannesma M, et al. Comparison of the effectiveness of radiotherapy with photons, protons and carbon-ions for non-small cell lung cancer: a meta-analysis. Radiother Oncol 2010;95:32-40.

52. Palma D, Lagerwaard F, Rodrigues G, et al. Curative treatment of Stage I non-small-cell lung cancer in patients with severe COPD: stereotactic radiotherapy outcomes and systematic review. Int J Radiat Oncol Biol Phys 2012;82:1149-56.

53. Guckenberger M, Kestin LL, Hope AJ, et al. Is there a lower limit of pretreatment pulmonary function for safe and effective stereotactic body radiotherapy for early-stage non-small cell lung cancer? J Thorac Oncol 2012;7:542-51.

54. Wulf J, Haedinger U, Oppitz U, et al. Stereotactic radiotherapy for primary lung cancer and pulmonary metastases: a noninvasive treatment approach in medically inoperable patients. Int J Radiat Oncol Biol Phys 2004;60:186-96.

55. Rusthoven KE, Kavanagh BD, Burri SH, et al. Multiinstitutional phase I/II trial of stereotactic body radiation therapy for lung metastases. J Clin Oncol 2009;27:1579-84.

56. Brown WT, Wu X, Fowler JF, et al. Lung metastases treated by CyberKnife image-guided robotic stereotactic radiosurgery at 41 months. South Med J 2008;101:376-82.

57. Yoon SM, Choi EK, Lee SW, et al. Clinical results of stereotactic body frame based fractionated radiation therapy for primary or metastatic thoracic tumors. Acta Oncol 2006;45:1108-14.

58. Onimaru R, Shirato H, Shimizu S, et al. Tolerance of 
organs at risk in small-volume, hypofractionated, imageguided radiotherapy for primary and metastatic lung cancers. Int J Radiat Oncol Biol Phys 2003;56:126-35.

59. Okunieff P, Petersen AL, Philip A, et al. Stereotactic Body Radiation Therapy (SBRT) for lung metastases. Acta Oncol 2006;45:808-17.

60. Qiu H, Katz AW, Chowdhry AK, et al. Stereotactic Body Radiotherapy for Lung Metastases from Colorectal Cancer: Prognostic Factors for Disease Control and Survival. Am J Clin Oncol 2018;41:53-8.

61. Palma DA, Olson R, Harrow S, et al. Stereotactic Ablative Radiotherapy for the Comprehensive Treatment of Oligometastatic Cancers: Long-Term Results of the SABR-COMET Phase II Randomized Trial. J Clin Oncol 2020;38:2830-8.

62. Amini A, Yeh N, Gaspar LE, et al. Stereotactic body radiation therapy (SBRT) for lung cancer patients previously treated with conventional radiotherapy: a review. Radiat Oncol 2014;9:210.

63. Owen D, Olivier KR, Mayo CS, et al. Outcomes of stereotactic body radiotherapy (SBRT) treatment of multiple synchronous and recurrent lung nodules. Radiat Oncol 2015;10:43.

64. Navarria P, Ascolese AM, Tomatis S, et al. Stereotactic body radiotherapy (sbrt) in lung oligometastatic patients: role of local treatments. Radiat Oncol 2014;9:91.

65. Siva S, MacManus M, Ball D. Stereotactic radiotherapy for pulmonary oligometastases: a systematic review. J Thorac Oncol 2010;5:1091-9.

66. Onishi H, Shirato H, Nagata Y, et al. Hypofractionated stereotactic radiotherapy (HypoFXSRT) for stage I nonsmall cell lung cancer: updated results of 257 patients in a Japanese multi-institutional study. J Thorac Oncol 2007;2:S94-100.

67. Videtic GM, Hu C, Singh AK, et al. A Randomized Phase 2 Study Comparing 2 Stereotactic Body Radiation Therapy Schedules for Medically Inoperable Patients With Stage I Peripheral Non-Small Cell Lung Cancer: NRG Oncology RTOG 0915 (NCCTG N0927). Int J Radiat Oncol Biol Phys 2015;93:757-64.

68. Filippi AR, Guerrera F, Badellino S, et al. Exploratory Analysis on Overall Survival after Either Surgery or Stereotactic Radiotherapy for Lung Oligometastases from Colorectal Cancer. Clin Oncol (R Coll Radiol) 2016;28:505-12.

69. Londero F, Grossi W, Morelli A, et al. Surgery versus stereotactic radiotherapy for treatment of pulmonary metastases. A systematic review of literature. Future Sci
OA 2020;6:FSO471.

70. Ahmed M, Liu Z, Afzal KS, et al. Radiofrequency ablation: effect of surrounding tissue composition on coagulation necrosis in a canine tumor model. Radiology 2004;230:761-7.

71. de Baère T, Aupérin A, Deschamps F, et al. Radiofrequency ablation is a valid treatment option for lung metastases: experience in 566 patients with 1037 metastases. Ann Oncol 2015;26:987-91.

72. Gillams A, Khan Z, Osborn P, et al. Survival after radiofrequency ablation in 122 patients with inoperable colorectal lung metastases. Cardiovasc Intervent Radiol 2013;36:724-30.

73. Petre EN, Jia X, Thornton RH, et al. Treatment of pulmonary colorectal metastases by radiofrequency ablation. Clin Colorectal Cancer 2013;12:37-44.

74. Inoue M, Nakatsuka S, Yashiro H, et al. Percutaneous cryoablation of lung tumors: feasibility and safety. J Vasc Interv Radiol 2012;23:295-302; quiz 305.

75. de Baere T, Tselikas L, Woodrum D, et al. Evaluating Cryoablation of Metastatic Lung Tumors in Patients-Safety and Efficacy: The ECLIPSE Trial--Interim Analysis at 1 Year. J Thorac Oncol 2015;10:1468-74.

76. de Baère T, Woodrum D, Tselikas L, et al. The ECLIPSE Study: Efficacy of Cryoablation on Metastatic Lung Tumors With a 5-Year Follow-Up. J Thorac Oncol 2021;16:1840-9.

77. Beckers PAJ, Versteegh MIM, Van Brakel TJ, et al. Multicenter Phase II Clinical Trial of Isolated Lung Perfusion in Patients With Lung Metastases. Ann Thorac Surg 2019;108:167-74.

78. Downey RJ, $\mathrm{Ng} \mathrm{KK}$, Kris MG, et al. A phase II trial of chemotherapy and surgery for non-small cell lung cancer patients with a synchronous solitary metastasis. Lung Cancer 2002;38:193-7.

79. Karim S, Nanji S, Brennan K, et al. Chemotherapy for resected colorectal cancer pulmonary metastases: Utilization and outcomes in routine clinical practice. Eur J Surg Oncol 2017;43:1481-7.

80. Shiomi K, Naito M, Sato T, et al. Effect of adjuvant chemotherapy after pulmonary metastasectomy on the prognosis of colorectal cancer. Ann Med Surg (Lond) 2017;20:19-25.

81. Gomez DR, Blumenschein GR Jr, Lee JJ, et al. Local consolidative therapy versus maintenance therapy or observation for patients with oligometastatic non-smallcell lung cancer without progression after first-line systemic therapy: a multicentre, randomised, controlled, 
phase 2 study. Lancet Oncol 2016;17:1672-82.

82. Gomez DR, Tang C, Zhang J, et al. Local Consolidative Therapy Vs. Maintenance Therapy or Observation for Patients With Oligometastatic Non-Small-Cell Lung Cancer: Long-Term Results of a Multi-Institutional, Phase II, Randomized Study. J Clin Oncol 2019;37:1558-65.

83. Weickhardt AJ, Scheier B, Burke JM, et al. Local ablative therapy of oligoprogressive disease prolongs disease control by tyrosine kinase inhibitors in oncogeneaddicted non-small-cell lung cancer. J Thorac Oncol 2012;7:1807-14.

84. Iyengar P, Kavanagh BD, Wardak Z, et al. Phase II trial of stereotactic body radiation therapy combined with erlotinib for patients with limited but progressive metastatic non-small-cell lung cancer. J Clin Oncol 2014;32:3824-30.

85. Kodet O, Němejcova K, Strnadová K, et al. The Abscopal Effect in the Era of Checkpoint Inhibitors. Int J Mol Sci 2021;22:7204.

86. Lee Y, Auh SL, Wang Y, et al. Therapeutic effects of ablative radiation on local tumor require CD8+ $\mathrm{T}$ cells: changing strategies for cancer treatment. Blood 2009;114:589-95.

87. Siva S, MacManus MP, Martin RF, et al. Abscopal effects of radiation therapy: a clinical review for the radiobiologist. Cancer Lett 2015;356:82-90.

88. Reynders K, Illidge T, Siva S, et al. The abscopal effect of local radiotherapy: using immunotherapy to make a rare event clinically relevant. Cancer Treat Rev 2015;41:503-10.

89. Bernstein MB, Krishnan S, Hodge JW, et al. Immunotherapy and stereotactic ablative radiotherapy

doi: $10.21037 /$ asj-21-81

Cite this article as: Bottini A, Parisi F, Cella E, Sacco G, Genova C. Management of pulmonary metastases: a narrative review on the oncologist's perspective. AME Surg J 2023;3:5.
(ISABR): a curative approach? Nat Rev Clin Oncol 2016;13:516-24.

90. Meacci E, Nachira D, Congedo MT, et al. Lung metastasectomy following kidney tumors: outcomes and prognostic factors from a single-center experience. J Thorac Dis 2017;9:S1267-72.

91. Procházková K, Vodička J, Fichtl J, et al. Outcomes for Patients after Resection of Pulmonary Metastases from Clear Cell Renal Cell Carcinoma: 18 Years of Experience. Urol Int 2019;103:297-302.

92. Lee JM, Tsuboi M, Brunelli A. Surgical Perspective on Neoadjuvant Immunotherapy in Non-Small Cell Lung Cancer. Ann Thorac Surg 2022;114:1505-15.

93. Reyes R, Reguart N. Neoadjuvant treatment of stage IIIA-N2 in EGFR-Mutant/ALK-rearranged non-small cell lung cancer. Transl Lung Cancer Res 2021;10:607-21.

94. Canino C, Perrone L, Bosco E, et al. Targeting angiogenesis in metastatic renal cell carcinoma. Expert Rev Anticancer Ther 2019;19:245-57.

95. Chebib R, Verlingue L, Cozic N, et al. Angiogenesis inhibition in the second-line treatment of metastatic colorectal cancer: A systematic review and pooled analysis. Semin Oncol 2017;44:114-28.

96. Tumati V, Iyengar P. The current state of oligometastatic and oligoprogressive non-small cell lung cancer. J Thorac Dis 2018;10:S2537-44.

97. Qiu B, Liang Y, Li Q, et al. Local Therapy for Oligoprogressive Disease in Patients With Advanced Stage Non-small-cell Lung Cancer Harboring Epidermal Growth Factor Receptor Mutation. Clin Lung Cancer 2017;18:e369-73. 
Supplementary

Table S1 Example of detailed search strategy for the purpose of this narrative review (NCBI-PubMed)

\begin{tabular}{ll}
\hline MeSH (Medical Subject Heading) combinations & Details \\
\hline Combination 1 & "Lung" AND "Metastases" AND "Oligometastasis" AND "Radiotherapy" \\
Combination 2 & "Lung" AND "Metastases" AND "Oligometastasis" AND "Surgery" \\
Combination 3 & "Lung" AND "Metastases" AND "Oligoprogression" AND "Radiotherapy" \\
Combination 4 & "Lung" AND "Metastases" AND "Oligoprogression" AND "Surgery" \\
Combination 5 & "Pulmonary" AND "Metastases" AND "Oligometastasis" AND "Radiotherapy" \\
Combination 6 & "Pulmonary" AND "Metastases" AND "Oligometastasis" AND "Surgery" \\
Combination 7 & "Pulmonary" AND "Metastases" AND "Oligoprogression" AND "Radiotherapy" \\
Combination 8 & "Pulmonary" AND "Metastases" AND "Oligoprogression" AND "Surgery"
\end{tabular}

